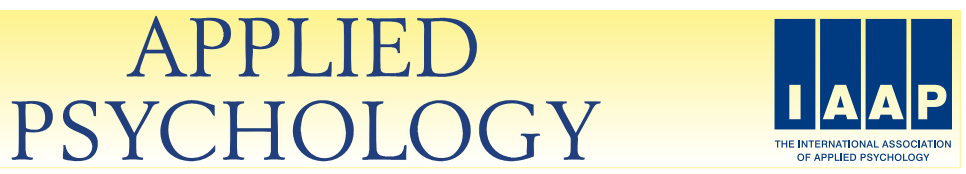

APPLIED PSYCHOLOGY: AN INTERNATIONAL REVIEW, 2011, 60 (2), 231-254 doi: $10.1111 /$ j.1464-0597.2010.00434.x

\title{
The Effects of Applicant Résumé Contents on Recruiters' Hiring Recommendations: The Mediating Roles of Recruiter Fit Perceptions
}

\author{
Wei-Chi Tsai* and Nai-Wen Chi \\ National Chengchi University, Taiwan
}

Tun-Chun Huang

National Taiwan University of Science and Technology, Taiwan

\author{
Ai-Ju Hsu \\ National Chiao Tung University, Taiwan
}

\begin{abstract}
The résumé is the most commonly used selection tool for organisations. Past studies have demonstrated that recruiter hiring recommendations can be predicted based on the content of applicant résumés. However, the mechanisms underlying the links between résumé contents and hiring recommendations remain unclear. The present study extends previous research by examining the mediating roles of recruiters' multi-faceted fit perceptions in a field setting. Data were collected from 216 organisational recruiters who participated in campus recruitment at seven universities in Taiwan. The results showed that applicant work experience and educational background increased recruiter hiring recommendations through recruiter perceived person-job (P-J) fit. In addition, applicant work experience predicted recruiter perceived person-organisation $(\mathrm{P}-\mathrm{O})$ fit, which in turn enhanced recruiter hiring recommendations.
\end{abstract}

\section{INTRODUCTION}

The résumé evaluation is the starting point of the selection process (Nemanick \& Clark, 2002). As the résumé content is considered to be evidence of an applicant's employability, it becomes one of the most commonly used tools in personnel selection (Cole, Rubin, Feild, \& Giles, 2007; Dipboye, 1992). Because applicants' résumés contain a wide range of information (Forbes,

* Address for correspondence: Wei-Chi Tsai, National Chengchi University, Department of Business Administration, 64, Chih-Nan Road, Section 2, Taipei 116, Taiwan. Email: weichi@ nccu.edu.tw 
2003), how recruiters perceive and make decisions based on that information is critical to the hiring process (Thoms, McMasters, Roberts, \& Dombkowski, 1999).

Previous research has demonstrated that certain contents of résumés influence recruiter decisions. For example, Thoms et al. (1999) found that applicants were more likely to be recommended for subsequent interviews when their résumés included descriptions such as job-related information, grade point average (GPA), and relevant coursework. Cole, Feild, Giles, and Harris (2004) also showed that résumés containing information about extracurricular activities increased recruiters' perceptions of candidate employability. Although these studies have provided preliminary evidence for the effects of résumé content on recruiter hiring recommendations, it remains unclear as to how and why such effects exist.

Résumé contents are among the most common information sources capable of producing dispositional attributions of the applicant (Nemanick \& Clark, 2002). These attributions lead recruiters to determine whether applicants fit with the demands of the job vacancy (i.e. person-job fit [P-J fit]) and/or organisational values (i.e. person-organisation fit [P-O fit]), which in turn positively predicts recruiters' hiring recommendations (Cole et al., 2007; Kristof, 1996). Moreover, applicants' life experiences or background information may enhance recruiters' similar-to-me effects toward these applicants (i.e. person-person fit [P-P fit]), which would increase recruiters' intentions to hire the applicants (Rynes, Barber, \& Varma, 2000). Hence, it is plausible that recruiters simultaneously consider applicants' multi-faceted fit during the résumé screening process (Cole et al., 2004; Kristof-Brown, 2000). Hence, recruiters' multiple fit perceptions could be potential mechanisms that link résumé contents to recruiter hiring recommendations.

The present study aims to contribute to the selection literature in three ways. First, we examine whether different résumé contents predict hiring recommendations through recruiter multiple fit perceptions toward applicants (i.e. $\mathrm{P}-\mathrm{J}$ fit, $\mathrm{P}-\mathrm{O}$ fit, and $\mathrm{P}-\mathrm{P}$ fit). This approach sheds new light on how and why résumé content leads to recruiters' hiring recommendations (Whetten, 1989). Although past studies have examined the mediating roles of $\mathrm{P}-\mathrm{J}$ fit and $\mathrm{P}-\mathrm{O}$ fit in the employment selection context (e.g. Higgins \& Judge, 2004; Kristof-Brown, 2000), we go a step further by introducing the fit between applicants and recruiters (i.e. P-P fit; Jansen \& Kristof-Brown, 2006) as another possible mechanism. Several studies have found that recruiters' perceived P-P fit indeed positively predicted their liking toward the applicants and intentions to hire applicants, even though they would not work with the applicants (e.g. Graves \& Powell, 1995; Howard \& Ferris, 1996). Hence, P-P fit is an important fit facet that should be taken into consideration in the résumé screening process. 
Second, previous résumé research has used data mainly from business college students (e.g. Cole et al., 2004; Cole, Feild, \& Stafford, 2005) or from students in a single management course (e.g. Nemanick \& Clark, 2002; Thoms et al., 1999). Because applicants' educational backgrounds and majors are very similar in these studies, these researchers did not take applicants' educational background into consideration when measuring the résumé contents. In the present study, we add applicant educational background as an additional dimension of résumé contents for two reasons. To begin with, as Brown and Campion (1994) found educational background to be one of the most widely used résumé items, and as we collected applicant data from various educational backgrounds and schools, it is meaningful to integrate this category into the résumé contents. In addition, in the context of Taiwan, it is quite common for organisations and online job-search websites to request information about applicants' educational background in the application forms. Adding this dimension helps to fully capture the construct domain of résumé content in Taiwan.

Finally, previous studies on résumé content have been conducted mainly as laboratory or field experiments with student samples taking the same courses (e.g. Cole et al., 2005; Nemanick \& Clark, 2002; Thoms et al., 1999). Consequently, résumés in these studies are limited to either certain types of applicant résumés (predominantly accounting and sales positions; e.g. Brown \& Campion, 1994) or résumés that are not collected from the actual job-search context (e.g. Cole et al., 2004, 2005; Thoms et al., 1999). Therefore, the realism and generalisability of research findings are relatively limited. To overcome these limitations, we conducted this study in a field setting of campus recruiting that includes organisational recruiters and actual applicant résumés for various job vacancies (i.e. engineering, sales, and administration). This approach strengthens the realism and generalisability of our findings (McGrath, 1982).

\section{THEORY AND HYPOTHESES}

\section{The Relationship between Résumé Content and Hiring Recommendations}

Résumé content is a major source from which recruiters can draw inferences about applicants' abilities, interests, and personality (Cole et al., 2005). For example, Brown and Campion (1994) found that recruiters tend to believe that an applicant's grades in major reflect his or her language and math abilities. Moreover, applicant extracurricular activities also strengthen recruiters' inferences of applicant quality and personality (Cole, Feild, Giles, \& Harris, 2003; Nemanick \& Clark, 2002). These résumé contents generate recruiters' inferences about applicant abilities or attributes, which in turn 
determine recruiters' judgments regarding applicant employability and their hiring recommendations (Cole et al., 2004, 2007).

Although the use of biodata and résumés for personnel selection has a long history, there is no generally agreed-upon consensus about what constitutes biodata or résumés (Breaugh, 2009). According to Mael (1991), the only attribute that defines a biodata or résumé item is that the item must reflect a current or past part of the person's life history. As Mael's definition is historical in nature, we employ the taxonomy developed by Cole and colleagues as a basis for understanding résumé contents (Cole et al., 2003, 2007). According to Cole and colleagues, résumé contents can be classified into three categories: academic achievement (the information pertaining to overall grades and scholastic awards), work experience (applicants' possession of work experiences), and activities (applicants' experiences in extracurricular activities). Moreover, we added a fourth category, namely, educational background (the highest degree the applicant holds and the "academic major"). The highest degree one has earned and the department the applicant graduated from can help recruiters infer the extent to which an applicant possesses necessary declarative knowledge to perform required tasks (Campbell, McCloy, Oppler, \& Sager, 1993). Such information can be hard to obtain from categories such as work experience or activities. Preliminary evidence suggests that information regarding educational background affects a recruiter's evaluation of both the applicant's ability and non-ability attributes (Brown \& Campion, 1994). Hence, we believe it is necessary to include this category to fully capture the construct domain of applicant résumés.

Résumé content may influence recruiter evaluations through two major mechanisms: impression management and similar-attraction effect. Although the effect of applicant impression management has been studied primarily in the context of employment interviews, researchers have noted that applicants may employ impression management tactics in preparing résumés in order to create a desirable image (Wayne \& Liden, 1995). For example, applicants are likely to emphasise their skills, knowledge, work experience, or past achievements that make them look more professional and more suitable for the job under consideration. Alternatively, they may also underscore their beliefs, personal values, or other characteristics that are thought to be consistent with the organisation's. Applicants can affect recruiters' P-J or P-O fit perceptions by promoting themselves, ingratiating themselves with the recruiter and the organisation, or both (Higgins \& Judge, 2004; KristofBrown, Barrick, \& Franke, 2002), which in turn can increase applicants' opportunities for landing subsequent job interviews or the job itself. Given that applicants are strongly motivated to present themselves in a positive light, it is reasonable to assume that the more detailed a résumé is, the more likely the applicant would be to receive a favorable evaluation. 
The similarity-attraction effect (Byrne, 1971), which is the tendency for recruiters to recruit applicants who reflect their own "self-image", can exert substantive influence on recruiter hiring decision-making processes (Rand \& Wexley, 1975). The similarity-attraction paradigm provides a parsimonious explanation for how and why people are attracted to and influenced by others during social interactions: When individuals share similar experiences, values, and beliefs with others, they are attracted to, and will have a positive evaluation of, one another based on the similarities. Past research has found that similarity in various aspects (e.g. personality, attitude, or demographic) predicts the applicant's job choice, as well as the recruiter's selection decision (e.g. Devendorf \& Highhouse, 2008). Research evidence also indicates that applicants with background information similar to that of recruiters are rated more favorably than those applicants who differ from recruiters in these aspects (Anderson \& Shackleton, 1990). Since applicants are more likely to present selected positive information in their résumés, such information could be a potential trigger for recruiters' favorable inferences. Accordingly, recruiters may perceive applicants to be similar to them because recruiters would consider applicants as possessing those desirable dispositions. In the following section, we provide both theoretical and empirical arguments to illustrate why the relationships between résumé content and recruiters' hiring recommendations are expected to hold.

\section{The Mediating Role of Perceived P-J Fit}

P-J fit is concerned with the fit between applicants' knowledge, skills, abilities (KSAs), and job requirements (Higgins \& Judge, 2004). Because P-J fit has been shown to predict an applicant's future performance (Kristof-Brown, Zimmerman, \& Johnson, 2005; Villanova, Bernardin, Johnson, \& Dahmus, 1994), recruiters are motivated to match applicants' KSAs with job requirements during the résumé screening processes (Werbel \& Gilliland, 1999).

Why would recruiters evaluate applicants' P-J fit according to applicants' résumé content? According to the complementary model of $\mathrm{P}-\mathrm{J}$ fit (Muchinsky \& Monahan, 1987), recruiters will search for applicants with necessary KSAs to offset a weakness or a requirement of the job. Hence, recruiters will look for specific résumé contents to determine whether the applicants possess KSAs complementary to job requirements. Within the résumé literature, Knouse (1994) showed that applicant work experience and educational background were positively related to recruiters' judgment of applicant jobrelated abilities. Kristof-Brown (2000) also found that applicant work experience and academic achievement influenced recruiters' perceptions of $\mathrm{P}-\mathrm{J}$ fit. Thus, recruiters should look to résumé content such as academic achievement, work experience, and educational background when considering applicants' fit with the job. In contrast, as extracurricular activities often

(C) 2010 The Authors. Applied Psychology: An International Review (C) 2010 International Association of Applied Psychology. 
help recruiters assess applicants' personality and values (Nemanick \& Clark, 2002), such information is less likely to affect recruiters' perceptions of P-J fit.

After evaluating the applicants' $\mathrm{P}-\mathrm{J}$ fit, recruiters will then decide whether or not to recommend these applicants for hire (Gatewood \& Feild, 2001). Because a better match between applicant KSAs and the job requirements may predict applicants' better future performance (Edwards, 1991; Villanova et al., 1994), recruiters are more likely to recommend those applicants with high levels of P-J fit (Werbel \& Gilliland, 1999). Hence, recruiters' subjective evaluations of $\mathrm{P}-\mathrm{J}$ fit tend to have positive effects on hiring recommendations (Kristof-Brown, 2000; Kristof-Brown et al., 2005). Hence, we propose the following hypothesis:

Hypothesis 1: Recruiter perceived $\mathrm{P}-\mathrm{J}$ fit mediates the relationships between applicants' résumé content (with regard to academic achievement, work experience, and educational background) and recruiter hiring recommendations.

\section{The Mediating Role of Perceived P-O Fit}

$\mathrm{P}-\mathrm{O}$ fit highlights the compatibility between applicants and organisational attributes (e.g. personality or values; Rynes \& Gerhart, 1990). The attractionselection-attrition (ASA) model (Schneider, 1987) argues that people are attracted to and selected by organisations whose desirable attributes are similar. Moreover, research has consistently found that selecting applicants with high levels of $\mathrm{P}-\mathrm{O}$ fit could predict not only lower levels of turnover intentions and absenteeism, but also higher levels of organisational commitment (Chatman, 1991; Kristof, 1996; Kristof-Brown et al., 2005). Therefore, to select applicants with suitable attributes, recruiters would refer to specific résumé content as the basis for making inferences about applicants' values or personality (Cole et al., 2003; Higgins \& Judge, 2004).

Recruiters may consider work experience as the means to assess applicants' $\mathrm{P}-\mathrm{O}$ fit because applicants' previous job choices may somehow reflect their particular values or preferences for organisations (Judge \& Cable, 1997). Empirical evidence has also shown that work experience positively predicts recruiter perceptions of applicants' P-O fit, supporting this argument (Adkins, Russell, \& Werbel, 1994; Bretz, Rynes, \& Gerhart, 1993; Kristof-Brown, 2000). In addition, when evaluating résumés, recruiters may interpret applicants' extracurricular activities as reflecting their personality and dispositions because activities partially reflect applicants' preferences, interests, and behavioral tendencies (Cole et al., 2003, 2004; Nemanick \& Clark, 2002). Thus, we expect that résumé content regarding work experience and work activities should predict recruiters' $\mathrm{P}-\mathrm{O}$ fit perceptions. Lastly, as applicants' academic achievement and educational background represent more direct evidence for applicants' KSAs than for 
their values or personality traits, then it is reasonable to assume that recruiters would not make extensive use of this information to judge $\mathrm{P}-\mathrm{O}$ fit (Kristof-Brown, 2000).

Finally, selecting applicants whose personalities or values are compatible with an organisational culture helps to create long-term employment and positive employee attitudes toward the organisation (Bowen, Ledford, \& Nathan, 1991; Kristof, 1996). As such, recruiters are likely to recommend the applicants who possess attributes that are compatible with the organisation (Higgins \& Judge, 2004). Past research has consistently demonstrated that recruiters' subjective evaluations of $\mathrm{P}-\mathrm{O}$ fit were positively related to subsequent hiring recommendations (e.g. Cable \& Judge, 1997; Kristof-Brown, 2000). Thus, we propose the following hypothesis:

Hypothesis 2: Recruiter perceived $\mathrm{P}-\mathrm{O}$ fit mediates the relationships between applicants' résumé content (with regard to work experience and activities) and recruiter hiring recommendations.

\section{The Mediating Role of Perceived P-P Fit}

Compared with the other types of fit, P-P fit has been relatively neglected in selection research (Jansen \& Kristof-Brown, 2006; Kristof-Brown et al., 2005). P-P fit focuses not only on the dyadic fit in the supervisor-subordinate relationships, but also on compatibility between applicants and recruiters (e.g. Graves \& Powell, 1988; Kristof-Brown et al., 2002). In the context of the current study, we define P-P fit as the similarity between applicants and recruiters.

We argue that information regarding applicant academic achievement and educational background may evoke recruiter $\mathrm{P}-\mathrm{P}$ fit perception because, on the one hand, recruiters might implicitly perceive themselves to be the "ideal employee" in the organisation (Sears \& Rowe, 2003); while on the other hand, applicants who provide relatively large amounts of positive information about their academic achievement and educational background are also more likely to be perceived as the "ideal employee" (Dalessio \& Imada, 1984; Sears \& Rowe, 2003). Based on the contention of the similarity-attraction paradigm (Byrne, 1971), when individuals share similar characteristics with others it helps prediction of their future behaviors, which leads to a quick evaluation by others (Schlenker, Brown, \& Tedeschi, 1975). Furthermore, similarity provides a sense of comfort and reduces interpersonal conflict in social interactions (Devendorf \& Highhouse, 2008). As such, recruiters would give similar applicants more favorable evaluations than dissimilar ones in order to enhance interpersonal harmony in the workplace. Consistent with the above reasoning, research has found that applicant résumé content such as academic achievement and educational background increases recruiter perceived P-P fit (Graves \& Powell, 1988, 1995; Kristof-Brown 
et al., 2002; Wade \& Kinicki, 1997); and perceived P-P fit has been shown to predict recruiter hiring recommendations (Garcia, Posthuma, \& Colella, 2008; Orpen, 1984).

In addition, the similarity-attraction paradigm also explains the association among applicant extracurricular activities, recruiter perceived P-P fit, and hiring recommendations. As mentioned earlier, extracurricular activities can be viewed as one important source for recruiters' judgments of applicant personality (Cole et al., 2003, 2004). When applicants provide more positive information about extracurricular activities on their résumés, recruiters will have more information to judge applicant attributes (Frank \& Hackman, 1975; Nemanick \& Clark, 2002). However, in order to make a good first impression on potential employers, applicants are motivated to present more job- or organisation-relevant extracurricular activities on their résumé. Accordingly, recruiters are likely to perceive these applicants as the "ideal employees" who possess desirable dispositions (Cole et al., 2003).

Moreover, as recruiters might consider themselves to be the "ideal employee" of the organisation (Rynes et al., 2000), they may perceive those applicants who present more positive extracurricular activities information to be more similar to them than those who do not. As a result, recruiters are more willing to recommend these applicants than those with few extracurricular activities (Cole et al., 2003; Graves \& Powell, 1995). Based on these arguments, we propose the following hypothesis:

Hypothesis 3: Recruiter perceived P-P fit mediates the relationships between applicants' résumé content (with regard to academic achievements, educational background, and extracurricular activities) and recruiter hiring recommendations.

\section{METHODS}

\section{Participants}

Participants were 226 recruiters (from 212 organisations) who were involved in campus recruiting activities at seven universities in Taiwan. These recruiters were in charge of hiring undergraduate or graduate students for engineering, sales, and administrative job vacancies. Most participants were HR recruiters $(84 \%)$ and were female $(67 \%)$, and the mean age was 32 . Participants generally spent about 30 per cent of their working time in screening résumés, and had an average of four years' experience in résumé screening.

\section{Procedure}

The fourth author collected the data from seven different sites where recruitment was taking place. The recruiters were invited to participate in this study.

(C) 2010 The Authors. Applied Psychology: An International Review (C) 2010 International Association of Applied Psychology. 
To avoid the potential problem of social desirability (Podsakoff, MacKenzie, Lee, \& Podsakoff, 2003), respondents were simply told that the purpose of this study was to identify factors that influenced recruiters' perceptions when screening résumés. When recruiters agreed to participate in the study, they were asked to randomly pull one résumé from all the résumés they had received on that day. The recruiters were asked to carefully review the selected résumé. If the selected résumé was from an applicant who had already been interviewed, then the recruiters were asked to take another résumé. The purpose of this step was to eliminate or minimise the possibility that the recruiters' interview-based impressions of an applicant would contaminate the recruiters' evaluation of résumé content. At the end of this process, recruiters reviewed a total of 226 résumés for entry-level jobs. With regard to the distribution of industry, 93 résumés $(41 \%)$ were prepared for positions in high-tech manufacturing plants, $37(16 \%)$ were for positions in computer or information technology companies, and $24(11 \%)$ were for positions in financial/insurance industries. Another 24 résumés (11\%) were prepared for positions in traditional manufacturing sectors. The remaining 48 résumés $(22 \%)$ were prepared for positions in industries such as mass media, retailing, and transportation. With respect to the types of job positions being sought, 137 résumés $(61 \%)$ were for engineering positions, $54(24 \%)$ were for sales positions, and $35(15 \%)$ were for administrative positions.

When reviewing a résumé, recruiters decided themselves how much time to spend on screening the résumé. Once they felt that they had sufficient information to form an opinion of the job applicant, they were asked to fill out the applicant-evaluation surveys in terms of résumé content, fit perceptions, and hiring recommendations. Since respondents' positive moods could have produced an artificial covariance in self-report measures, we collected the information about the recruiters' positive mood and treated it as a control variable to alleviate potential common method variance problems (Podsakoff et al., 2003; Podsakoff \& Organ, 1986).

\section{Measurement}

Résumé Content. To measure résumé content, we slightly modified the résumé scale used by Brown and Campion (1994) and Cole et al. (2003, 2007). Specifically, we combined some items that overlapped with other items, and removed those that were somewhat inappropriate in the Taiwanese context.

For the résumé items in the first three categories, we followed Brown and Campion's (1994) and Cole et al.'s $(2003,2007)$ approach by asking recruiters to evaluate the extent to which each aspect of résumé content was reported in the résumé using a 5-point Likert scale $(1=$ none, $5=$ considerable amount; 
see Brown \& Campion, 1994; Cole et al., 2003, 2007). Because applicants are likely to use their résumé to build a positive image for favorable evaluations, we assumed that the greater the level of résumé information perceived by recruiters, the more favorable their evaluation of applicants would be. The items for each résumé category are described below.

Academic Achievement. We used two items (i.e. received scholastic awards; Overall GPA) to measure the content of the academic achievement category. For "Overall GPA", the recruiters were asked to record this information directly from the résumé. In order to ensure that the "Overall GPA" item was consistent with the rating on the aforementioned 5-point scale, we followed Cole et al.'s (2003) approach by assigning the code 1 to applicants who did not list the overall GPA on their résumés. If the overall GPA was listed on the résumé, then it was divided into quartiles and the lowest quartile was assigned a value of 2 , the next highest equal to 3 , and so forth. We removed the items "Was on the Dean's list" and "GPA in major" since it is unusual for applicants to provide such information on a résumé in Taiwan.

Work Experience. We measured this category with two items. The first item was, "Has work experience from working in college, from holding a summer internship, or from holding a full-time job", which is derived from three conceptually overlapping items from Cole et al.'s $(2003,2007)$ scales (i.e. "Has held summer internship", "Has full-time work experience", and "Worked while in college"). The second item was, "Demonstrated personal accomplishments in past work experiences".

Activities. We used four items to measure this résumé category (e.g. Membership in college clubs; Member of professional societies). Given that social fraternity and sorority establishments are not common in Taiwan, we excluded the item, "Was the member of a social fraternity/sorority", in the subsequent analyses.

Educational Background. As mentioned earlier, we added educational background as the fourth category of résumé content. Although past studies did not include items pertaining to "educational background" (i.e. bachelor or master degree, and the academic major) when measuring résumé content, we followed Brown and Campion's (1994) step of adding two items to this category (e.g. the applicant possesses a job-related degree) using a 5-point Likert scale $(1=$ strongly disagree, $5=$ strongly agree $)$.

Finally, Cronbach's alphas for each résumé content category were .83, .59, .85 , and .72 , respectively, which were similar to Cole et al.'s (2007) findings.

Perceived Person-Job Fit. We measured perceived person-job fit using Kristof-Brown's (2000) three-item scale (e.g. "This applicant fits the demands 
of the job", and "I am confident that this applicant is qualified for this job"). Responses were made on a 6-point scale $(1=$ strongly disagree, $6=$ strongly agree). The Cronbach's alpha for this scale was .92.

Perceived Person-Organisation Fit. We measured perceived personorganisation fit using Cable and DeRue's (2002) three-item scale (e.g. "The applicant's personal values match my organisation's values and culture"). Responses were made on a 6-point scale $(1=$ strongly disagree, $6=$ strongly agree). The Cronbach's alpha for this scale was .94.

One may question whether recruiters have the ability to judge the $\mathrm{P}-\mathrm{O}$ fit on the basis simply of résumé content. However, Bretz et al. (1993) indicated that recruiters, in forming their perceptions of $\mathrm{P}-\mathrm{O}$ fit, refer to résumé information such as applicants' work experience and activities.

Perceived Person-Person Fit. We measured perceived person-person fit on the basis of Howard and Ferris' (1996) four-item scale (e.g. "This applicant and I have many of the same beliefs and values"). Responses were made on a 6 -point scale $(1=$ strongly disagree, $6=$ strongly agree $)$. The Cronbach's alpha for this scale was .89 .

Hiring Recommendations. We adopted four items from Tsai, Chen, and Chiu (2005) to assess recruiters' intentions in terms of hiring recommendations. Sample items include, "I do consider this applicant suitable for hiring by this organisation", and "I am likely to recommend the applicant to enter the subsequent selection process". Responses were made on a 6-point scale $(1=$ strongly disagree, $6=$ strongly agree $)$. The Cronbach's alpha was .75 for this scale.

\section{Control Variable}

Podsakoff and Organ (1986) suggested that how respondents answer an item can obviously be affected by their current mood. In order to reduce the common method variance (CMV) problems caused by respondents' moods, ${ }^{1}$ we measured recruiters' positive moods on the basis of Watson, Clark, and Tellegen's (1988) 10-item scale (e.g. interested, excited). Responses were

\footnotetext{
${ }^{1}$ Since controlling for positive moods might also partial out some meaningful variances between positive moods and other variables (Podsakoff et al., 2003), we performed an additional analysis that excluded positive moods from the proposed models. The results remained identical to our original results. Similarly, the inclusion of recruiters' experience in screening résumés and the percentage of work time spent on screening résumés as additional control variables had almost no effect on the findings of this study. In an effort to obtain a reasonably parsimonious model, we will not report the effects of these two recruiter characteristics in the following sections.
} 
made on a 4-point scale so that we could assess recruiters' moods at the time of the given responses $(1=$ not at all, $4=$ extremely/ much $)$. The Cronbach's alpha was .93 .

\section{Data Analysis}

In order to test the hypotheses, we used LISREL 8.54 with maximum likelihood estimation; specifically, we conducted structural equation modeling (SEM) analyses. All analyses were based on the correlation matrix, and scale scores were treated as single indicators of the respective constructs (see Chen $\&$ Klimoski, 2003). To account for random measurement errors of all indicators, we followed Bollen's (1989) suggestion of setting the random measurement error of each indicator equal to one minus the reliability; moreover, the paths from the latent variables to indicators were set equal to the square root of the reliability.

\section{Confirmatory Factor Analysis}

To evaluate the discriminant and convergent validity of measures, we conducted a series of confirmatory factor analyses (CFAs) in which all study variables were included. First, we compared the fit indexes between the proposed nine-factor model (four résumé contents, three fit perceptions, hiring recommendation, and positive moods) and the eight-factor model (in which the items of $\mathrm{P}-\mathrm{J}$ fit and hiring recommendation were loaded onto one factor). The CFA results showed that the nine-factor model $\left(\chi^{2}[491]=\right.$ 906.86, $\chi^{2} / \mathrm{df}=1.85 ; \mathrm{CFI}=.96, \mathrm{NFI}=.93$, RMSEA $=.06$ ) fit the data better than the eight-factor model $\left(\chi^{2}[499]=979.84, \chi^{2} / \mathrm{df}=1.96\right.$; CFI $=.95$, NFI $=.92, \mathrm{RMSEA}=.07)$. The chi-square tests also showed that the $\chi^{2}$ decrement between the hypothesised nine-factor model and the eight-factor model was statistically significant $\left(\Delta \chi^{2}=72.98, \Delta \mathrm{df}=8, p<.01\right)$, which indicated that recruiters could distinguish between $\mathrm{P}-\mathrm{J}$ fit and hiring recommendation.

In addition, we followed Kristof-Brown (2000) by conducting a CFA to examine whether or not the recruiters could distinguish between different types of fit perceptions. Specifically, we compared the fit indexes between the proposed nine-factor model, an eight-factor model (in which $\mathrm{P}-\mathrm{J}$ and $\mathrm{P}-\mathrm{O}$ were loaded onto one factor, with P-P loaded onto the other), and a sevenfactor model (in which all fit items were loaded onto one factor). The CFA results showed that the proposed nine-factor model fit the data better than both the eight-factor model $\left(\chi^{2}[499]=1530.46, \chi^{2} / \mathrm{df}=3.06\right.$; CFI $=.92$, NFI $=.88, \mathrm{RMSEA}=.10)$ and the seven-factor model $\left(\chi^{2}[506]=2202.81, \chi^{2} / \mathrm{df}=\right.$ $4.35 ; \mathrm{CFI}=.89, \mathrm{NFI}=.85, \mathrm{RMSEA}=.12$ ). The chi-square tests showed that the $\chi^{2}$ decrements among the hypothesised nine-factor model, the eightfactor model, and the seven-factor model were statistically significant $\left(\Delta \chi^{2}=\right.$ 
623.6, $\Delta \mathrm{df}=8, p<.01 ; \Delta \chi^{2}=1295.95, \Delta \mathrm{df}=15, p<.01$, respectively). These results suggested that perceived $\mathrm{P}-\mathrm{J}, \mathrm{P}-\mathrm{O}$, and $\mathrm{P}-\mathrm{P}$ fit can reasonably be treated as separate variables.

Finally, since all study variables were collected from the same source, we followed Podsakoff et al.'s (2003) approach to examine the severity of CMV with an unmeasured latent method factor. In order to solve the problem of model identification, we fixed the item loadings of the method factor to be equal (Podsakoff et al., 2003). Despite the fact that the fit indices of the ten-factor model (i.e. the proposed nine factors plus the additional unmeasured method factor) were slightly better $\left(\chi^{2}[489]=895.27, \chi^{2} / \mathrm{df}=1.83\right.$; CFI $=.97, \mathrm{NFI}=.93$, RMSEA $\left.=.06, \Delta \chi^{2}=11.59, \Delta \mathrm{df}=2, p<.01\right)$ than those of the original nine-factor model, it should be noted that the factor loadings between the hypothesised nine factors and the corresponding items were still statistically significant after partialling out the method effects. Moreover, the relationships between the hypothesised nine factors remained unchanged. Therefore, although the method factor did improve the model fit, it did not change the factor loadings and the expected relationship of the hypothesised nine factors, suggesting that CMV did not adversely affect the validity of the present study (Podsakoff et al., 2003).

Taken together, these results suggested that recruiters can distinguish between résumé content, fit perceptions, and hiring recommendations. Moreover, the factor loadings of all items in the nine-factor model were statistically significant $(p<.01)$, suggesting that the convergent validity of all measures was acceptable (Bagozzi, Yi, \& Phillips, 1991).

\section{RESULTS}

Table 1 presents the means, standard deviations, reliabilities, and correlations of the study's variables. Correlations between résumé contents and hiring recommendations were all positive and significant $(r=.20$ to .35 , all $p$ s $<.01)$. In addition, fit perceptions were all positively and significantly correlated with hiring recommendations $(r=.43$ to .72 , all $p \mathrm{~s}<.01)$. As for the control variable, the relationships among recruiters' positive moods and $\mathrm{P}-\mathrm{J}$ fit, $\mathrm{P}-\mathrm{O}$ fit, $\mathrm{P}-\mathrm{P}$ fit, and hiring recommendations were all positive and significant $(r=.25$ to .39 , all $p$ s $<.01)$.

\section{Hypotheses Testing}

We tested the hypotheses with SEM. Figure 1 presents all hypothesised paths (including the control variable). Since we made no prediction as to whether the relationships in the hypothesised model represented full or partial mediation, we tested both models, a full mediation model (Figure 1) and a partial mediation model. The partial mediation model differed from the full 


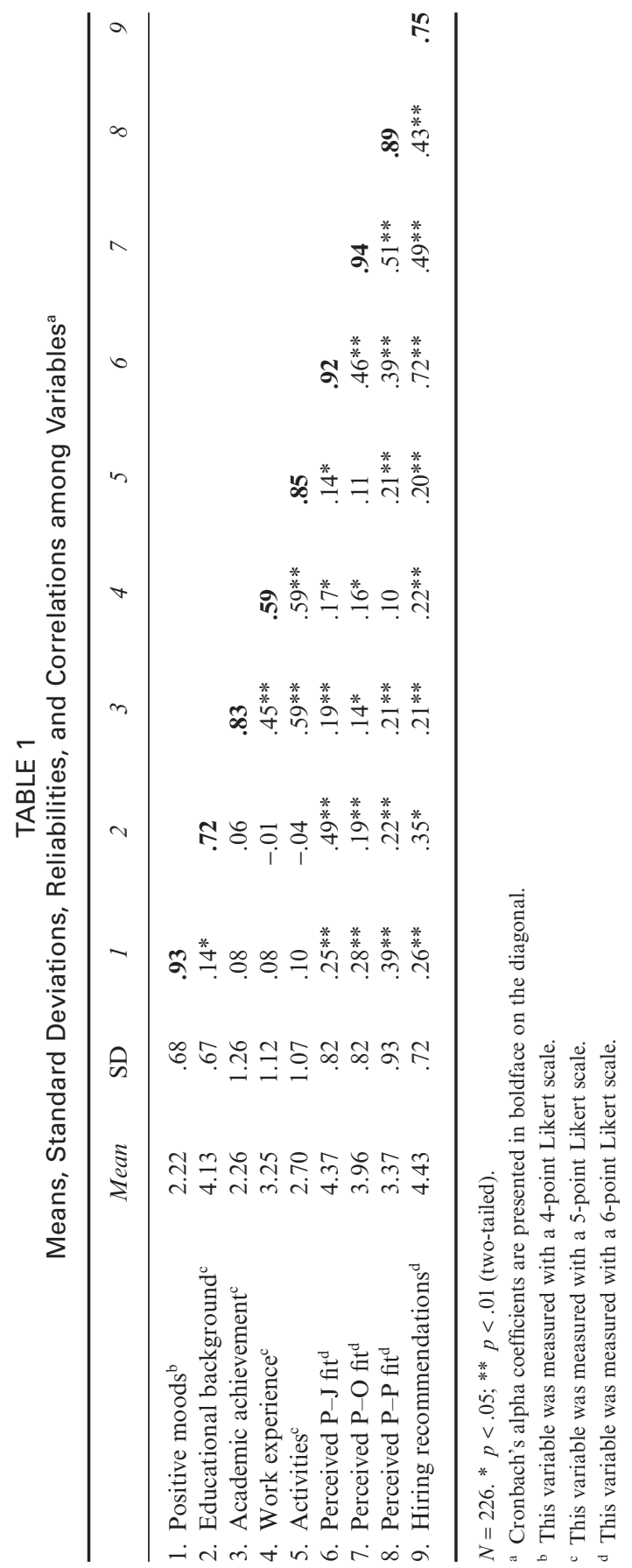

(C) 2010 The Authors. Applied Psychology: An International Review (C) 2010 International Association of Applied Psychology. 


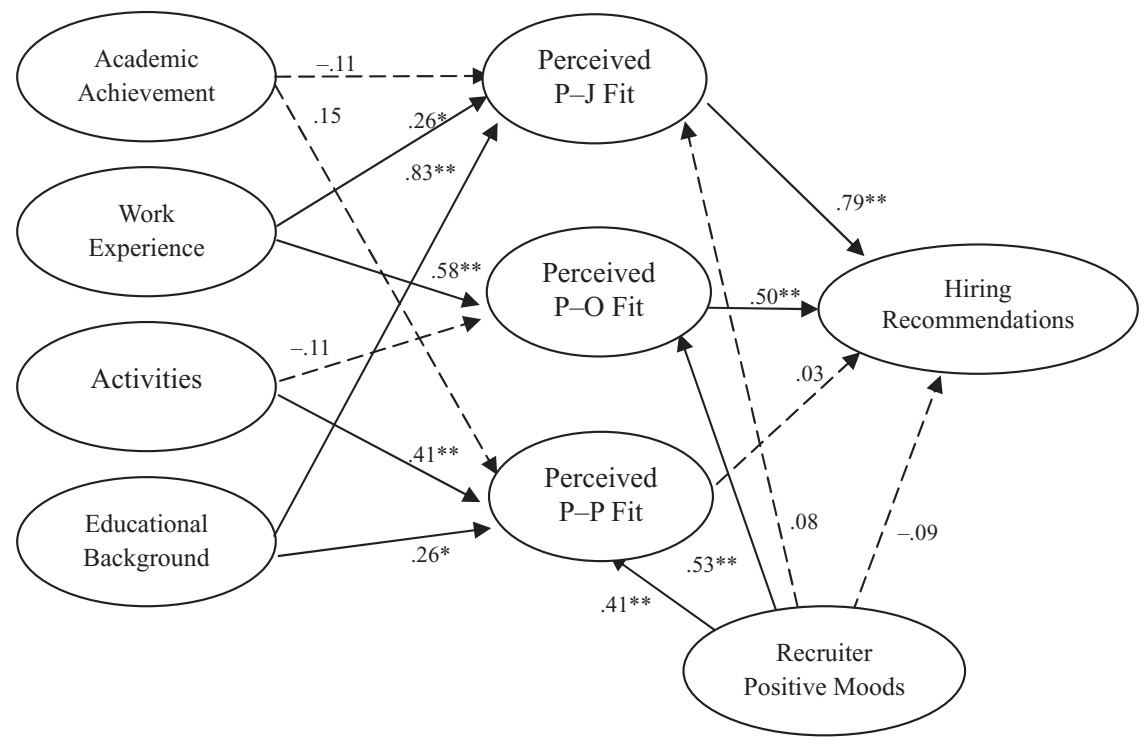

FIGURE 1. Structural equation model with maximum likelihood estimates (standardised) ${ }^{\mathrm{a}}$

a All indicators and correlations among the exogenous variables are not included. The dotted lines represent the non-significant paths. ${ }^{*} p<.05$; ** $p<.01$ (two-tailed).

mediation model in that the former had four direct paths from academic achievement, work experience, extracurricular activities, and educational background to hiring recommendations.

Results showed that both the full mediation model $\left(\chi^{2}[11]=41.78 ; \chi^{2} / \mathrm{df}\right.$ $=3.79 ; \mathrm{CFI}=.98, \mathrm{NFI}=.97, \mathrm{RMSEA}=.11)$ and the partial mediation model $\left(\chi^{2}[7]=40.35 ; \chi^{2} / \mathrm{df}=5.76 ; \mathrm{CFI}=.97, \mathrm{NFI}=.96, \mathrm{RMSEA}=.15\right)$ provided an adequate fit to the data. ${ }^{2}$ However, the chi-square difference test showed that the chi-square decrement between the partial and full mediation model was not statistically significant $\left(\Delta \chi^{2}=1.43, \Delta \mathrm{df}=4, p>.05\right)$. Furthermore, all coefficients of the four direct paths (i.e. from résumé content to hiring recommendations) were non-significant $(\beta=-.09, .15,-.05$, and .02 , all $p \mathrm{~s}>.05)$.

2 Although the RMSEA values of both the partial and full mediation models exceed the standard of .10 (Steiger, 1989), Kenny (2008) noted that the RMSEA value could be misleading when the degree-of-freedom of the model is small. As the degrees-of-freedom of the two models were relatively small (i.e. 11 and 7, respectively), the large RMSEA values should be interpreted with some caution. 
Therefore, to ensure the parsimony of the model, we concluded that the full mediation model was the better model, and we used it to examine our hypotheses.

For Hypothesis 1 (see Figure 1), the path coefficients of work experience $(\beta=.26, p<.05)$ and educational background $(\beta=.83, p<.01)$ to $\mathrm{P}-\mathrm{J}$ fit, and the path from $\mathrm{P}-\mathrm{J}$ fit to hiring recommendations $(\beta=.79, p<.01)$ were all positive and significant. However, the path from academic achievement to P-J fit was not significant. In addition, we tested the significance of hypothesised indirect effects with the Sobel test (Sobel, 1982). Results showed that both work experience and educational background had significant indirect effects through $\mathrm{P}-\mathrm{J}$ fit on hiring recommendations ( $z=1.97$ and 4.67, respectively; all $p \mathrm{~s}<.05)$. Taken together, $\mathrm{P}-\mathrm{J}$ fit mediated the linkage between work experience, educational background, and hiring recommendations, offering partial support for Hypothesis 1.

As for Hypothesis 2, the path from work experience to $\mathrm{P}-\mathrm{O}$ fit $(\beta=.58, p$ $<.01)$ and the path from $\mathrm{P}-\mathrm{O}$ fit to hiring recommendations $(\beta=.50, p<.01)$ were both positive and significant. However, the path between activities and $\mathrm{P}-\mathrm{O}$ fit was not significant. We also conducted a Sobel test to examine the indirect effects of the hypothesised relationships. The result showed that work experience had significant indirect effects through $\mathrm{P}-\mathrm{O}$ fit on hiring recommendations $(z=3.02, p<.05)$. Therefore, Hypothesis 2 also received partial support.

Finally, Hypothesis 3 examined the mediating role of P-P fit. As shown in Figure 1 , activities $(\beta=.41, p<.01)$ and educational background $(\beta=.26$, $p<.01)$ were positively related to $\mathrm{P}-\mathrm{P}$ fit. However, the path from academic achievement to P-P fit and the path coefficient between P-P fit and hiring recommendations were not significant. Therefore, Hypothesis 3 was not supported.

\section{DISCUSSION}

We briefly discuss contributions and theoretical implications of the present study in this section. First, the present study contributes to the selection research by simultaneously examining the mechanisms linking applicant résumé content and hiring recommendations. Our findings suggest that recruiters make inferences about applicants' $\mathrm{P}-\mathrm{J}$ fit and $\mathrm{P}-\mathrm{O}$ fit on the basis of the information revealed in résumés (e.g. work experience and educational background), which in turn predict recruiters' intentions to recommend the applicants.

As expected, results showed that recruiters' perceived P-J fit mediated the effects of applicant work experiences and educational background on recruiter hiring recommendations. However, we found no support for the relationship between academic achievement (e.g. GPA) and P-J fit. Although 
Kristof-Brown's (2000) experimental study found that recruiters use applicant KSAs, such as GPA, more frequently to assess applicants' P-J fit than $\mathrm{P}-\mathrm{O}$ fit, several empirical studies have documented that GPA was unrelated to recruiters' P-J fit perceptions (e.g. Higgins \& Judge, 2004; Kristof-Brown et al., 2002). It is plausible that the relationship between academic achievement (e.g. GPA) and perceived P-J fit depends on some undetected moderators. For example, McKinney, Carlson, Mecham, D'Angelo, and Connerley (2003) found that the in-major GPA was more strongly associated with recruiters' screening decisions $(\rho=.18)$ than the relationship between overall GPA and screening decisions $(\rho=.06)$. It may be that recruiters view in-major GPA as a more effective indicator of job-related KSAs than overall GPA. In the present study, we did not collect information with respect to the in-major GPA. Instead, only the overall GPA was included as an indicator of the academic achievement category. This might lead to the non-significant relationship between academic achievement and perceived P-J fit. To verify our proposition, we encourage future researchers to re-examine this relationship by including in-major GPA as another indicator when measuring the academic achievement category.

In addition, the results revealed that recruiters' perceived $\mathrm{P}-\mathrm{O}$ fit mediated the relationships between applicants' work experience and hiring recommendations. This finding supports Kristof-Brown's (2000) argument that recruiters also used applicants' job-related information (i.e. work experience) when assessing applicants' $\mathrm{P}-\mathrm{O}$ fit. However, we found that activities were not related to $\mathrm{P}-\mathrm{O}$ fit. It is plausible that the effects of applicants' activities on recruiters' perceptions of $\mathrm{P}-\mathrm{O}$ fit might be moderated by some undetected moderators (e.g. job vacancy). For example, given that extracurricular activities are indicators of applicants' extraversion (Cole et al., 2003), recruiters may rely more on extracurricular activities as a basis of their judgments of $\mathrm{P}-\mathrm{O}$ fit when job vacancies require occupants to be sociable and to interact with others in a smooth manner (e.g. managers or salespersons) than when jobs do not have such requirements (e.g. engineers or computer programmers).

Although applicants' activities and educational background have positive associations with recruiters' perceived P-P fit, academic achievement did not predict recruiters' perceptions of $\mathrm{P}-\mathrm{P}$ fit. Furthermore, it is also surprising that $\mathrm{P}-\mathrm{P}$ fit was unrelated to hiring recommendations. In this regard, we propose two possible explanations. To begin with, as recruiters do not have to work with the applicants, it would be more important for recruiters to select the applicants who fit with the job or the organisation (i.e. recruiters' duty) rather than fit with the recruiters. Another possible explanation may be the high correlations between P-P and P-J fit $(r=.39)$ and between P-P and P-O fit $(r=.51)$. Thus, the unique effects of $\mathrm{P}-\mathrm{P}$ fit on hiring recommendations may become non-significant after controlling for the effects of $\mathrm{P}-\mathrm{J} / \mathrm{P}-\mathrm{O}$ fit. 
The second contribution of the present study is the finding that educational background has pervasive effects on recruiter P-J and P-P perceptions. Thus, the importance of educational background on applicant résumés has been overlooked in previous research (e.g. Cole et al., 2003, 2004). It seems that recruiters make extensive use of applicant educational background information in terms of forming their fit perceptions toward applicants. As a result, our findings highlighted the importance of treating educational background as an independent dimension of résumé content.

The third contribution of the present study is to test our model with the actual recruiters and résumés for various job vacancies (i.e. sales and administrative, engineering) in the real employment context. This approach helps to strengthen the realism of our findings (McGrath, 1982). Finally, some scholars have raised the issue as to whether recruiters can distinguish different facets of fit from their overall fit perceptions (e.g. Higgins \& Judge, 2004; Kristof-Brown, 2000). Although our study is not designed to directly address this issue, the results of our study provided some answers to this question. For example, the results of CFA on recruiter fit perceptions showed that the nine-factor model ( $\mathrm{P}-\mathrm{J}, \mathrm{P}-\mathrm{O}$, and $\mathrm{P}-\mathrm{P}$ fit) fit the data better than did either the eight-factor model (i.e. $\mathrm{P}-\mathrm{J}$ fit and $\mathrm{P}-\mathrm{O}$ fit items loaded on the same factor) or the seven-factor model (i.e. all fit items loaded on the same factor). Moreover, all three facets of fit perceptions were predicted by reference to different résumé content and had different magnitudes of effects on recruiters' hiring recommendations. Therefore, the results of the present study suggested that $\mathrm{P}-\mathrm{J}, \mathrm{P}-\mathrm{O}$, and $\mathrm{P}-\mathrm{P}$ fit perceptions can be distinguished from each other and should be treated as separate facets of fit perceptions. This approach responded to scholars' calls for the need to simultaneously test the effects of multi-faceted fit perceptions in the selection research (e.g. Anderson, Lievens, van Dam, \& Ryan, 2004; Jansen \& Kristof-Brown, 2006).

\section{Practical Implications}

Our results can provide some practical implications for both organisations and job seekers. From an organisational perspective, recruiters can distinguish between different types of fit among applicants. This indicates that recruiters will simultaneously consider applicants' various characteristics on the basis of the applicants' résumé content. As research shows that recruiters' perceptions of $\mathrm{P}-\mathrm{J}$ and $\mathrm{P}-\mathrm{O}$ fit are good predictors of applicants' future performance and retention (Arthur, Bell, Villado, \& Doverspike, 2006; Huffcutt, Conway, Roth, \& Stone, 2001), organisations should train recruiters to assess applicants' job-related qualifications and applicants' value congruence with organisations, and provide recruiters with clearer guidance as to what defines a good extent of $\mathrm{P}-\mathrm{J}$ and $\mathrm{P}-\mathrm{O}$ fit. 
From the viewpoint of the applicant, in order to obtain job offers, applicants should customise their résumé so that there is a match between the applicants and either the jobs or the organisations for which the applicants are applying. That is, applicants are advised to highlight relevant aspects of their educational background, work experience, and activities to increase recruiters' perceived $\mathrm{P}-\mathrm{J}$ and $\mathrm{P}-\mathrm{O}$ fit.

\section{Limitations and Future Research}

Some limitations of this study should be noted. First, in order to collect data from the actual résumé screening process, we measured all variables on the basis of self-reports from the same recruiters. Thus, the CMV problems may have influenced the results (Podsakoff et al., 2003). We addressed this issue in the following three ways. To begin with, in order to avoid the illusory correlations caused by respondents' implicit assumptions (i.e. respondents may assume that the measurements are associated with each other and may consequently introduce this assumption into their ratings), we told respondents that the purpose of the study was only "to identify the factors that determine recruiters' perceptions in the process of résumé screening". In addition, we have compared the fit indexes between the nine-factor model and the one-factor model (see the section on the confirmatory factor analysis). The one-factor model would have fit the data as well as the proposed nine-factor model if CMV significantly influenced our findings. However, the results showed that the one-factor model did not significantly fit the data better than our hypothesised model. Finally, and most importantly, we have controlled for the effects of recruiter positive moods (i.e. a major source of CMV; Podsakoff et al., 2003) in the structural equation model. As a result of these actions, we believe that CMV would not adversely influence our findings.

The second limitation is the ambiguity of the causal inference created by the cross-sectional design. However, from a theoretical standpoint, reversed causality inferences are less plausible in the proposed model. That is, it is less reasonable to argue that recruiters' hiring recommendations lead to recruiters' fit perceptions, which in turn trigger changes in evaluations of applicant résumé content. Although we believe that this limitation would not have changed our findings, we suggest that future research tackle this issue through the use of an experimental design.

The relatively low reliability of the work experience measure suggests that the relationships between work experience and other variables of interest may have been attenuated. Fortunately, the SEM analysis helps to correct for attenuation caused by imperfect measurements (Bollen, 1989); hence, we believe that the concern of attenuation caused by low reliability should be minimal. However, it would be beneficial for future research to add more work experience items in order to increase scale reliability (Cortina, 1993). 
Readers may wonder why the present study's scale items were operationalised in different ways across different résumé contents. ${ }^{3}$ For instance, items pertaining to work experience involve the quantity of the applicants' work experience. In contrast, those belonging to educational background are designed to gauge the extent to which the applicant possesses a job-related degree. In our view, the reason underlying Brown and Campion's (1994) and Cole et al.'s $(2003$, 2007) development of these seemingly different items concerns the dearth of evidence regarding what is the best way to measure various facets of résumé content (Breaugh, 2009). Although the conceptual framework of work experience measures was initially developed to explain the relationships between job performance and various operationalisations of work experience (i.e. amount, time, and type of work experience; Quinones, Ford, \& Teachout, 1995), this framework may be of help in the design of better measures of résumé content. Future research may, for example, directly examine which type of résumé content item best predicts recruiters' hiring recommendations: the amount of extracurricular activities, or the type of extracurricular activities? We believe this type of research should promote a more refined and integrated conceptualisation of résumé content.

To expand the current findings, future research may consider exploring questions such as: Will recruiters use the same standard to evaluate résumés for different job vacancies? As each job requires a different set of attributes and skills for their incumbents, we expect that the type of job vacancy might moderate the associations between résumé content and recruiter fit perceptions. To answer this question, we suggest that future researchers collect résumés from various job vacancies and conduct a multi-sample SEM analysis using a larger sample size (Jöreskog \& Sörbom, 1999) to test the strengths of the résumé content-fit perceptions associations across different job types. Moreover, since recruiters' evaluations of résumé content will influence organisational hiring decisions (Cole, Feild, Giles, \& Harris, 2009), it will be fruitful to examine whether the résumé content predicts applicants' future job performance or turnover. To investigate such research questions, future research could use a longitudinal research design to collect data on résumé content and outcomes (i.e. performance and turnover) at different points in time, and examine the effects of different résumé contents on applicants' future job performance and turnover. Specifically, we expect that educational background and work experience might predict applicants' job performance because these categories reflect applicants' KSAs (Kristof-Brown, 2000), while activities could predict applicants' turnover since this category reflects their personality traits such as extraversion, neuroticism, and conscientiousness (Cole et al., 2003, 2009).

${ }^{3}$ We thank an anonymous reviewer for raising this issue.

(C) 2010 The Authors. Applied Psychology: An International Review (C) 2010 International Association of Applied Psychology. 
In conclusion, the present research sheds light on the mechanisms (i.e. fit perceptions) that link résumé content to recruiter hiring recommendations. Future research could explore additional moderators (i.e. different types of job vacancies) to further clarify the boundary conditions of the proposed model.

\section{REFERENCES}

Adkins, C.L., Russell, C.J., \& Werbel, J.D. (1994). Judgments of fit in the selection process: The role of work value congruence. Personnel Psychology, 47, 605-623.

Anderson, N., Lievens, F., van Dam, K., \& Ryan, A.M. (2004). Future perspectives on employee selection: Key directions for future research and practice. Applied Psychology: An International Review, 53, 925-951.

Anderson, N., \& Shackleton, V. (1990). Decision making in the graduate selection interview: A field study. Journal of Occupational Psychology, 63, 63-76.

Arthur, W. Jr., Bell, S.T., Villado, A.J., \& Doverspike, D. (2006). The use of personorganization fit in employment decision making: An assessment of its criterionrelated validity. Journal of Applied Psychology, 91, 786-801.

Bagozzi, R.P., Yi, Y., \& Phillips, L.W. (1991). Assessing construct validity in organizational research. Administrative Science Quarterly, 36, 421-458.

Bollen, K.A. (1989). Structural equations with latent variables. New York: Wiley.

Bowen, D.E., Ledford, G.E., \& Nathan, B.R. (1991). Hiring for the organization not the job. Academy of Management Executive, 5, 35-51.

Breaugh, J.A. (2009). The use of biodata for employee selection: Past research and future directions. Human Resource Management Review, 19, 219-231.

Bretz, R.D., Rynes, S.L., \& Gerhart, B. (1993). Recruiter perceptions of applicant fit: Implications for individual career preparation and job search behavior. Journal of Vocational Behavior, 43, 310-327.

Brown, B.K., \& Campion, M.A. (1994). Biodata phenomenology: Recruiters' perceptions and use of biographical information in résumé screening. Journal of Applied Psychology, 79, 897-908.

Byrne, D. (1971). The attraction paradigm. New York: Academic Press.

Cable, D.M., \& DeRue, D.S. (2002). The convergent and discriminant validity of subjective fit perceptions. Journal of Applied Psychology, 87, 875-884.

Cable, D.M., \& Judge, T.A. (1997). Interviewers' perceptions of person-organization fit and organizational selection decisions. Journal of Applied Psychology, 82, 546 561.

Campbell, J.P., McCloy, R.A., Oppler, S.H., \& Sager, C.E. (1993). A theory of performance. In N. Schmitt \& W.C. Borman (Eds.), Personnel selection in organizations (pp. 35-70). San Francisco, CA: Jossey-Bass.

Chatman, J. (1991). Matching people and organizations: Selection and socialization in public accounting firms. Administrative Science Quarterly, 36, 459-484.

Chen, G., \& Klimoski, R.J. (2003). The impact of expectations on newcomer performance in teams as mediated by work characteristics, social exchanges, and empowerment. Academy of Management Journal, 46, 591-607.

Cole, M.S., Feild, H.S., Giles, W.F., \& Harris, S.G. (2003). Using recruiter assessments of applicant résumé content to predict applicant mental ability and big five

(C) 2010 The Authors. Applied Psychology: An International Review (C) 2010 International Association of Applied Psychology. 
personality dimensions. International Journal of Selection and Assessment, 11, 78-86.

Cole, M.S., Feild, H.S., Giles, W.F., \& Harris, S.G. (2004). Job type and recruiters' inferences of applicant personality drawn from résumé biodata: Their relationships with hiring recommendations. International Journal of Selection and Assessment, 12, 363-367.

Cole, M.S., Feild, H.S., Giles, W.F., \& Harris, S.G. (2009). Recruiters' inferences of applicant personality based on résumé screening: Do paper people have a personality? Journal of Business and Psychology, 24, 5-18.

Cole, M.S., Feild, H.S., \& Stafford, J.O. (2005). Validity of résumé reviewers' inferences concerning applicant personality based on résumé evaluation. International Journal of Selection and Assessment, 13, 321-324.

Cole, M.S., Rubin, R.S., Feild, H.S., \& Giles, W.F. (2007). Recruiters' perceptions and use of applicant résumé information: Screening the recent graduate. Applied Psychology: An International Review, 56, 319-343.

Cortina, J.M. (1993). What is coefficient alpha? An examination of theory and applications. Journal of Applied Psychology, 78, 98-104.

Dalessio, A., \& Imada, A. (1984). Relationships between interview selection decisions and perceptions of applicant similarity to an ideal employee and self: A field study. Human Relations, 37, 67-80.

Devendorf, S.A., \& Highhouse, S. (2008). Applicant-employee similarity and attraction to an employer. Journal of Occupational and Organizational Psychology, 81, 607-617.

Dipboye, R.L. (1992). Selection interviewing: Process perspectives. Cincinnati, OH: Southwestern.

Edwards, J.R. (1991). Person-job fit: A conceptual integration, literature review, and methodological critique. In C.L. Cooper \& I.T. Robertson (Eds.), International review of industrial and organizational psychology (pp. 283-357). New York: John Wiley and Sons.

Forbes, C. (2003). Video résumé: Seeing is believing. Canadian HR Reporter, 16, 12-13.

Frank, L.L., \& Hackman, J.R. (1975). Effect of interviewer-interviewee similarity on interviewer objectivity in college admission interviews. Journal of Applied Psychology, 60, 356-360.

Garcia, M.F., Posthuma, R.A., \& Colella, A. (2008). Fit perceptions in the employment interview: The role of similarity, liking, and expectations. Journal of Occupational and Organizational Psychology, 81, 173-189.

Gatewood, R.D., \& Feild, H.S. (2001). Human resource selection (3rd edn.). Chicago, IL: The Dryden Press.

Graves, L.M., \& Powell, G.N. (1988). An investigation of sex discrimination in recruiters' evaluations of actual applicants. Journal of Applied Psychology, 73, 20-29.

Graves, L.M., \& Powell, G.N. (1995). The effect of sex similarity on recruiters' evaluations of actual applicants: A test of the similarity-attraction paradigm. Personnel Psychology, 48, 85-98.

Higgins, C.A., \& Judge, T.A. (2004). The effect of applicant influence tactics on recruiter perceptions of fit and hiring recommendations: A field study. Journal of Applied Psychology, 89, 622-632. 
Howard, J.L., \& Ferris, G.R. (1996). The employment interview context: Social and situational influences on interviewer decisions. Journal of Applied Social Psychology, 26, 112-136.

Huffcutt, A.I., Conway, J.M., Roth, P.L., \& Stone, N.J. (2001). Identification and meta-analytic assessment of psychological constructs measured in employment interviews. Journal of Applied Psychology, 86, 897-913.

Jansen, K.J., \& Kristof-Brown, A. (2006). Toward a multidimensional theory of person-environment fit. Journal of Managerial Issues, 18, 193-212.

Jöreskog, K.G., \& Sörbom, D. (1999). LISREL 8 user's reference guide. Chicago, IL: Scientific Software.

Judge, T.A., \& Cable, D.M. (1997). Applicant personality, organizational culture, and organizational attraction. Personnel Psychology, 50, 359-394.

Kenny, D.A. (2008, January 2009). Measuring model fit. Retrieved 1 June 2009, from http://davidakenny.net/cm/fit.htm.

Knouse, S.B. (1994). Impression of the résumé: The effects of applicant education, experience, and impression management. Journal of Business and Psychology, 2, 183-196.

Kristof, A.L. (1996). Person-organization fit: An integrative review of its conceptualizations, measurement, and implications. Personnel Psychology, 49, 1-49.

Kristof-Brown, A.L. (2000). Distinguishing between recruiters' perceptions of person-job and person-organization fit. Personnel Psychology, 53, 643-671.

Kristof-Brown, A.L., Barrick, M.R., \& Franke, M. (2002). Applicant impression management: Dispositional influences and consequences for recruiter perceptions of fit and similarity. Journal of Management, 28, 27-46.

Kristof-Brown, A.L., Zimmerman, R.D., \& Johnson, E.C. (2005). Consequences of individuals' fit at work: A meta-analysis of person-job, person-organization, person-group, and person-supervisor fit. Personnel Psychology, 58, 281-342.

McGrath, J.E. (1982). Dilemmatics: The study of research choices and dilemmas. In J. McGrath, J. Martin, \& R. Kulka (Eds.), Judgment calls in research (pp. 69-102). Beverly Hills, CA: Sage.

McKinney, A.P., Carlson, K.D., Mecham, R.L. III, D’Angelo, N.C., \& Connerley, M.L. (2003). Recruiters' use of GPA in initial screening decisions: Higher GPAs don't always make the cut. Personnel Psychology, 56, 823-845.

Mael, F.A. (1991). A conceptual rationale for the domain and attributes of biodata items. Personnel Psychology, 44, 763-792.

Muchinsky, P.M., \& Monahan, C.J. (1987). What is person-environment congruence? Supplementary versus complementary models of fit. Journal of Vocational Behavior, 31, 268-277.

Nemanick, R.C., \& Clark, E.M. (2002). The differential effects of extracurricular activities on attributions in résumé evaluation. International Journal of Selection and Assessment, 10, 206-217.

Orpen, C. (1984). Attitude similarity, attraction, and decision-making in the employment interview. Journal of Psychology, 117, 111-120.

Podsakoff, P.M., MacKenzie, S.B., Lee, J., \& Podsakoff, N. (2003). Common method biases in behavioral research: A critical review of the literature and recommended remedies. Journal of Applied Psychology, 88, 879-903. 
Podsakoff, P.M., \& Organ, D.W. (1986). Self-reports in organizational research: Problems and prospects. Journal of Management, 12, 531-544.

Quinones, M.A., Ford, J.K., \& Teachout, M.S. (1995). The relationship between work experience and job performance: A conceptual and meta-analytic review. Personnel Psychology, 48, 887-910.

Rand, T.M., \& Wexley, K.N. (1975). Demonstration of the effect, "similar-to-me", in simulated employment interviews. Psychological Reports, 36, 535-544.

Rynes, S.L., Barber, A.E., \& Varma, G.H. (2000). Research on the employment interview: Usefulness for practice and recommendations for future research. In C.L. Cooper \& E.A. Locke (Eds.), Industrial and organizational psychology: Linking theory with practice (pp. 250-277). Malden, MA: Blackwell.

Rynes, S.L., \& Gerhart, B. (1990). Interviewer assessments of applicant "fit": An exploratory investigation. Personnel Psychology, 43, 13-45.

Schlenker, B.R., Brown, R.C., Jr., \& Tedeschi, J.T. (1975). Attraction and expectations of harm and benefits. Journal of Personality and Social Psychology, 32, 664-670.

Schneider, B. (1987). The people make the place. Personnel Psychology, 40, 437-453.

Sears, G.J., \& Rowe, P.M. (2003). A personality-based similar-to-me effect in the employment interview: Conscientiousness, affect- versus competence-mediated interpretations, and the role of job relevance. Canadian Journal of Behavioural Science, 35, 13-24.

Sobel, M.E. (1982). Asymptotic confidence intervals for indirect effects in structural equation models. In S. Leinhardt (Ed.), Sociological methodology (pp. 290-312). San Francisco, CA: Jossey-Bass.

Steiger, J.H. (1989). Structural model evaluation and modification: An interval estimation approach. Multivariate Behavioral Research, 25, 173-180.

Thoms, P., McMasters, R., Roberts, M.R., \& Dombkowski, D.A. (1999). Résumé characteristics as predictors of an invitation to interview. Journal of Business and Psychology, 13, 339-356.

Tsai, W.C., Chen, C.C., \& Chiu, S.F. (2005). Exploring boundaries of the effects of applicant impression management tactics in job interviews. Journal of Management, 31, 108-125.

Villanova, P., Bernardin, H.J., Johnson, D.L., \& Dahmus, S.A. (1994). The validity of a measure of job compatibility in the prediction of job performance and turnover of motion picture theater personnel. Personnel Psychology, 47, 73-90.

Wade, K.J., \& Kinicki, A.J. (1997). Subjective applicant qualifications and interpersonal attraction as mediators within a process model of interview selection decisions. Journal of Vocational Behavior, 50, 23-40.

Watson, D., Clark, L.A., \& Tellegen, A. (1988). Development and validation of brief measures of positive and negative affect: The PANAS scales. Journal of Personality and Social Psychology, 54, 1063-1070.

Wayne, S.J., \& Liden, R.C. (1995). Effects of impression management on performance ratings: A longitudinal study. Academy of Management Journal, 38, 232-260.

Werbel, J.D., \& Gilliland, S.W. (1999). Person-environment fit in the selection process. Research in Personnel and Human Resources Management, 17, 209-243.

Whetten, D.A. (1989). What constitutes a theoretical contribution? Academy of Management Review, 14, 490-495. 